\title{
Penentuan Tingkat Buta Warna Pada Citra Ishihara Berbasis HSV dan Algoritma Color Filtering
}

\author{
Alfian Syaifudin ${ }^{1)}$; Yustina Retno Wahyu Utami ${ }^{2)}$; Teguh Susyanto ${ }^{3)}$ \\ ${ }^{1,2)}$ Program Studi Teknik Informatika, STMIK Sinar Nusantara Surakarta \\ 3) Program Studi Sistem Informatika, STMIK Sinar Nusantara Surakarta \\ 1),alfian.syaif@gmail.com; ${ }^{2)}$,yustina_retno@sinus.ac.id; ${ }^{3)}$,teguh@sinus.ac.id;
}

\begin{abstract}
Currently, the use of computer media for measuring the level of color blindness for the recruitment of prospective workers in companies/organizations or the selection of prospective students in educational institutions is still rare. Most methods used to measure the level of color blindness still use conventional methods without involving a lot of computer media. The reason is that the level of color blindness measuring devices is still not affordable for companies or educational institutions. Based on this fact, a proposed method for measuring color blindness using computer media is by applying the Color Filtering algorithm to the HSV color space on the Ishihara images. The purpose of this paper is to design and build applications to detect the level of color blindness using the Color Filtering algorithm. The color filtering algorithm is an image processing technique that is used to manipulate an image based on the specific color obtained from a color space. The use of HSV color space is used because the human eye uses Hue to refer to colors known to humans, such as red and green. This property reflects the colors captured by the human eye that respond to various wavelength values of light. The results of this paper are the application of the Color Filtering algorithm to Ishihara-based HSV images expressed as highly relevant for detecting the level of a person's color blindness.
\end{abstract}

Keywords : color blind test, Color Filtering, Hue Saturation Value (HSV), color space.

\section{PENDAhuluan}

Lazim terjadi di setiap organisasi secara periodik menyelenggarakan proses seleksi masuk, di mana perusahaan merekrut tenaga pegawai, sekolah atau perguruan tinggi menyaring calon siswa atau mahasiswa yang memiliki persyaratan atau kecakapan akademis tertentu. Media yang digunakan dalam tahapan seleksi dalam perusahaan/organisasi juga telah banyak memanfaatkan teknologi seperti Computer Based Test (CBT). Banyak keterbatasan dalam CBT saat ini, Salah satunya, jarang ditemui penggunaan media komputer untuk mengukur tingkat buta warna. Tes buta warna untuk mengukur tingkat kesehatan mata yang dapat melihat dan membedakan pigmen dalam jumlah besar. Siswa yang tidak dapat membedakan warna kabel dan resistor dengan gelang warna berbeda yang merupakan komponen dasar dalam praktikum yang membutuhkan kepekaan terhadap persepsi warna akan berakibat fatal bagi pembuatan jaringan (Purnamasari, 2015).

Dalam tes buta warna ada beberapa tipe buta warna dari buta warna monokrom atau buta warna penuh yaitu hanya dapat membedakan 3 intensitas warna (hitam, putih, dan abuabu), Protanamali yang merupakan kelemahan warna merah yaitu kelemahan pada sel kerucut untuk merefleksikan warna merah. Deuteranomali yang merupakan kelemahan warna hijau yaitu kelemahan pada sel kerucut untuk merefleksikan warna hijau. Tritanomali yang merupakan kelemahan warna biru yaitu kelemahan ada sel kerucut untuk merefleksikan warna biru (Prabawati, 2015). Dari empat jenis buta warna dasar ini dapat disimpulkan bahwa sebuah tes yang dapat menentukan buta warna atau tidaknya seorang dapat menjadi acuan untuk melewati seleksi penerimaan.

Tujuan dalam penelitian ini adalah merancang dan membuat aplikasi penerapan metode Color Filtering untuk membedakan penderita buta warna dan mata normal. 
Algoritma Color filtering merupakan sebuah teknik pengolahan citra yang dipakai untuk memanipulasi suatu citra berdasarkan warna spesifik yang di dapat dari sebuah ruang warna. Pengunaan ruang warna HSV di pakai karena mata manusia menggunakan Hue merujuk ke warna yang di kenal manusia, seperti merah dan hijau. Properti ini mencerminkan warna yang ditangkap oleh mata manusia yang menanggapi berbagai nilai panjang gelombang cahaya (Nana dkk., 2016).

\section{TINJAUAN PUSTAKA}

Usulan penelitian dengan metode Color Filtering dalam Ruang HSV dan plate Ishihara ini mengacu pada beberapa penelitian sebelumnya meliputi penelitian yang diusulkan oleh (Sulistyawati, 2018), deteksi penyakit malaria dengan mengolah citra dari sampel darah pasien.

Dasar acuan penelitian kedua yaitu usulan dari (Nana dkk., 2016) membahas tentang membuat sebuah aplikasi sebagai metode pembelajaran untuk simulasi permainan gitar dengan mengimplementasikan algoritma Color Filtering untuk menentukan titik pada penanda jari tangan agar dapat dilakukan proses pencocokan terhadap titik kord gitar yang sesuai dengan bantuan webcam (Andriessen, 2013). Dari masalah di atas di buatlah sebuah aplikasi yang mengunakan Color Filtering untuk mengatur penanda jari tangan sebagai titik penentu sebuah warna untuk pencocokan terhadap titik kord gitar.

Atmojo (2016) menyatakan bahwa Pembangunan aplikasi tes buta warna dengan metode Ishihara berbasis komputer bertujuan untuk kegiatan tes buta warna yang menghasilkan kesimpulan normal, buta warna parsial dan buta warna total, dan hasil tes tersimpan di suatu database komputer. Metode untuk tes buta warna yang dipakai adalah metode yang ditemukan oleh Dr. Shinobu Ishihara yaitu metode Ishihara (Atmojo, 2016).

Usulan (Mutrofin dkk., 2015) tentang klasifikasi tumbuhan berdasarkan daun masih menjadi tantangan untuk diteliti. Salah satu klasifikasi tumbuhan berdasarkan daun hanya melihat pada fitur bentuk, jika dataset daun menggunakan dataset Flavia, hal itu cukup, karena hanya terdiri dari warna hijau daun saja. Faktanya, daun yang ada memiliki warna dan tekstur yang beragam, seperti pada dataset Foliage. Penelitian sebelumnya dalam mengekstraksi warna berdasarkan ruang warna RGB (Red Gren Blue). Pada penelitian ini diusulkan ekstraksi fitur warna berdasarkan ruang warna HSV (Hue Saturation Value), karena ruang warna HSV lebih baik dibandingkan dengan ruang warna RGB (Mutrofin dkk., 2015). Ekstraksi fitur tekstur menggunakan GLCM (Gray Level Co-occurrence Matrix).

Penelitian yang dilakukan oleh (Purnamasari, 2015), mengusulkan penyusunan langkah-langkah tes buta warna dengan mengunakan komputer. Tes yang dilakukan mengunakan batasan-batasan tertentu dan disusun secara manual oleh operator sebagai dasar penilaian.

\subsection{Color Filtering}

Color Filtering merupakan salah satu algoritma yang digunakan dalam bidang pengolahan citra digital. Algoritma ini merupakan filter yang digunakan untuk memfilter warna yang diinginkan pada gambar atau citra berdasarkan nilai komponen pada HSV (Kadir \& Susanto, 2013). Kombinasi HSV inilah yang kemudian dijadikan filter sebagai penentu sebuah warna diloloskan atau tidak. Color Filtering di gunakan di pengolahan citra yang dipakai untuk memanipulasi suatu citra berdasarkan warna spesifik. Cara kerjanya adalah dengan membandingkan komponen warna setiap pixel citra dengan warna spesifik. Proses Color Filtering digunakan dalam pendeteksian untuk memfilter warna RGB (Red Green Blue) (Nana dkk., 2016). 


\section{METODE PENELITIAN}

Tahapan kerja penelitian dengan algoritma Color Filtering dalam ruang HSV diilustrasikan pada Gambar 1. Langkah langkah dalam membuat plate ishihara baru adalah sebagai berikut :

1. Masukkan data berupa image plate original ishihara yang akan di konversi menjadi plate baru

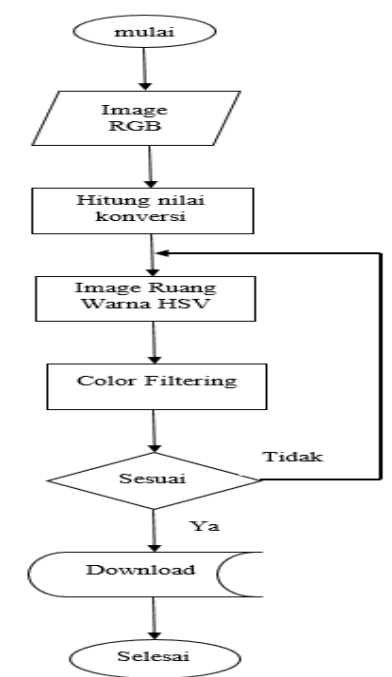

Gambar 1. Flowchart Plate Ishihara baru

2. Tentukan nilai hitungan konversi awal untuk mentransformasi dari RGB ke HSV dengan menggunakan Persamaan (1). Diasumsikan koordinat-koordinat R, G, B [0,1] adalah berurutan merah, hijau, biru dalam ruang warna RGB, dengan max adalah nilai maksimum dari nilai red, green, blue, dan min adalah nilai minimum dari nilai red, green, blue.

$$
\begin{aligned}
V & =\max \{R, G, B\} \\
\delta & =V-\min \{R, G, B\} \\
S & =\frac{\delta}{V}
\end{aligned}
$$

3. Untuk memperoleh sudut hue[0,360] yang tepat untuk ruang warna HSV.

Berdasarkan ilustrasi Gambar 2 terkait representasi ruang warna HSV, apabila R, G, dan B bernilai sama, maka warna menjadi keabuan yang membentuk intensitas putih. Warna tersebut hanya warna putih, akan memiliki nilai saturation nol. Ketika nilai-nilai RGB berbeda, maka warna yang dihasilkan nilai saturation yang tinggi. Jika salah satu dari nilai-nilai RGB bernilai nol, maka saturation bernilai 1 . Hue didefinisikan sebagai nilai-nilai pecahan disekitar lingkaran dimulai dari red, yang memiliki hue bernilai nol. Tabel 1 menjabarkan besaran nilai hue berdasarkan setiap ruang warna.

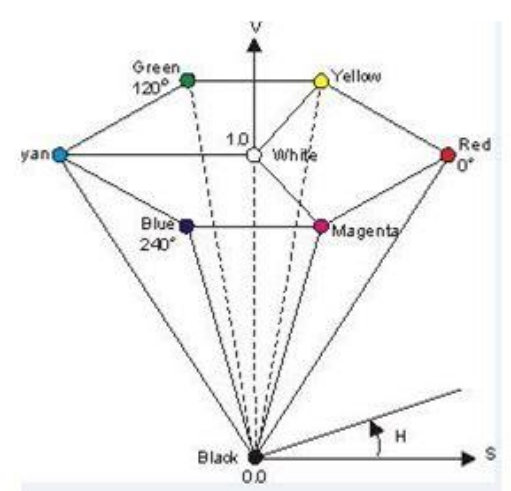

Gambar 2. Representasi Ruang Warna HSV (Nana et al., 2016) 
Tabel 1. Tabel Warna Hue

\begin{tabular}{l|r}
\hline \multicolumn{1}{c|}{ Warna } & \multicolumn{2}{|c}{ Hue } \\
\hline Red & 0 \\
Red & 0 \\
Yelow & 0,1667 \\
Green & 0,3333 \\
Cyan & 0,5 \\
Blue & 0,6667 \\
Magenta & 0,8333 \\
\hline
\end{tabular}

4. Hitung image dengan nilai hue yang sudah di tetapkan seperti pada contoh kasus.

5. Tentukan apakah plate sudah sesuai atau tidak. Ketika sudah sesuai masuk ke tombol download atau kembali ke seting image ruang HSV.

6. Mengambil data ke harddrive untuk kemudian di upload kedalam sistem untuk di jadikan plate soal.

\section{HASIL DAN PEMBAHASAN}

Pada hasil pembahasan ini adalah data perancangan sistem secara keseluruhan yaitu sebagai berikut :

\subsection{Penyusunan pilihan soal berdasarkan gambar Ishihara mengunakan Color Filtering dalam ruang warna HSV}

a. Keping Ishihara

Dari sebuah keeping ishihara kita bisa melihat 1 hingga 3 angka yang berbeda tergantung dari jenis warna pada keping, intensitas warna pada bagian-bagian keping dan dari penglihatan peserta tes. Dari sini pemilihan soal di lakukan dengan menentukan keping-keping Ishihara sebagai acuan awal pembuatan soal. Di karenakan keping paten dari Dr.ishihara atau original plate yang terdiri dari 38 keping tidak semua mengunakan angka.

b. Transformasi RGB ke HSV

Untuk mentransformasi dari RGB ke HSV. Diasumsikan koordinat-koordinat R, G, $\mathrm{B}[0,1]$ adalah berurutan merah, hijau, biru dalam ruang warna RGB, dengan max adalah nilai maksimum dari nilai red, green, blue, dan min adalah nilai minimum dari nilai red, green, blue. Untuk memperoleh sudut hue[0,360] yang tepat untuk ruang warna HSV, menggunakan rumus seperti pada Persamaan (2).

$$
h(\text { hue })=\left\{\begin{array}{cr}
0, & \text { jika max }=\min \\
60^{\circ}\left(\frac{\mathrm{G}-\mathrm{B}}{\max -\min } \bmod 6\right), & \text { jika max }=R \\
60^{\circ}\left(\frac{\mathrm{B}-\mathrm{R}}{\max -\min }+2\right), & \text { jika } \max =G \\
60^{\circ}\left(\frac{\mathrm{R}-\mathrm{G}}{\max -\min }+4\right), & \text { jika } \max =0
\end{array}\right.
$$

Nilai-nilai untuk s dan v pada HSV didefinisikan pada Persamaan (3).

$$
s(\text { saturation })= \begin{cases}0, & \text { jika } \max =\min \\ \frac{\max -\min }{V}, & \text { jika tidak } V(\text { value })=\max \end{cases}
$$

Rumus di atas menghasilkan nilai value dan saturation dalam jangkauan RGB $[0,1]$. Kalikan dahulu dengan 255 untuk memperoleh nilai dengan jangkauan RGB [0,255]. Misalnya ingin ditransformasikan $\operatorname{RGB}(65,27,234)$ ke dalam bentuk HSV, maka langkahnya adalah sebagai berikut : 
Setiap nilai $\operatorname{RGB}(65,27,234)$ diubah dalam jangkauan $[0,1]$ dengan membagi setiap nilai dengan 255 , menjadi

$\left(\frac{65}{255}, \frac{27}{255}, \frac{234}{255}\right)=(0.255,0.106,0.918)$

$\max =$ nilai $B($ blue $)=0.918$,

$\min =$ nilai $G($ green $)=0.106$,

$\max -\min =0.918-0.106=0.812$

$\operatorname{RGB}(0.255,0.106,0.918)$ ini yang akan ditransformasikan ke bentuk HSV.

$h($ hue $)=60^{\circ} x\left(\frac{\mathrm{R}-\mathrm{G}}{\max -\min }+4\right)$, karena $\max =B($ blue $)$

$h($ hue $)=60^{0} x\left(\frac{0.255-0.106}{0.812}+4\right)=251^{0}$

$v($ value $)=\max , \quad$ maka $v($ value $)=0.918$

$s($ saturation $)=\frac{\max -\min }{V}, \quad$ karena $\max <>\min$, maka $s($ saturation $)=\frac{0.812}{0.918}=0.885$

sehingga nilai $\operatorname{RGB}(65,27,234)$ ditransformasikan menjadi $\operatorname{HSV}(251,0.885,0.918)$ dengan jangkauan RGB (0,1) (Mutrofin dkk., 2015).

c. Gambaran pengunaan Color Filtering RGB dalam Ruang HSV diilustrasikan pada Gambar 3.

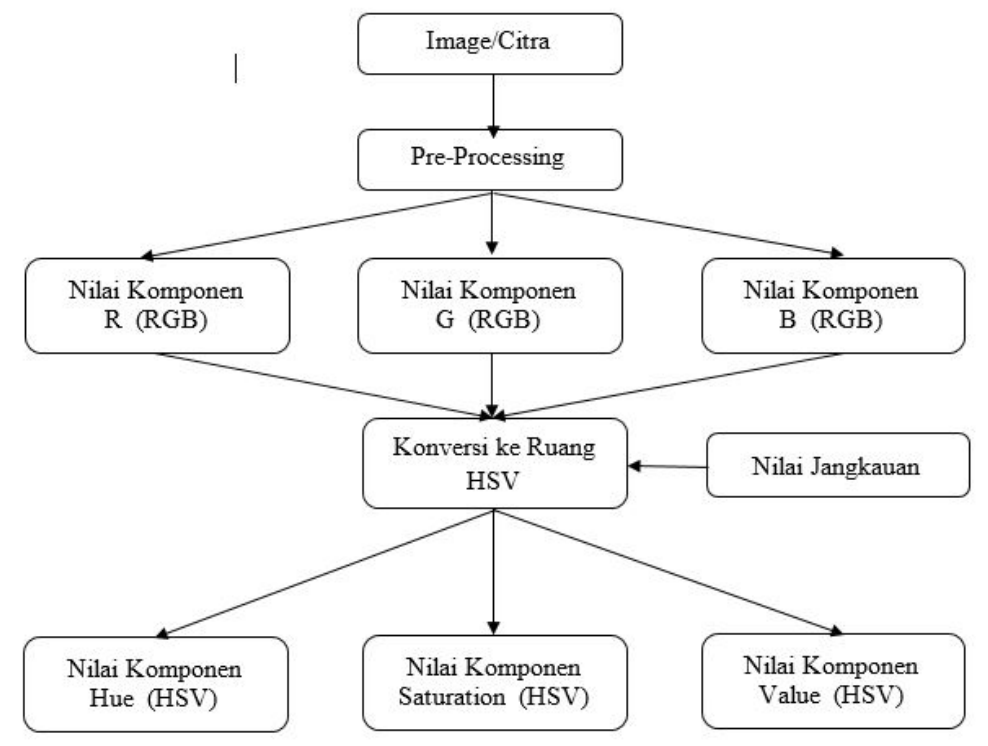

Gambar 3. Diagram Proses Color Filtering RGB dalam Ruang HSV

d. Menentukan Nilai jangkauan pada ruang HSV

Untuk mendapatkan nilai hue, perhatikan Persamaan (4) berikut.

Jika $R=V$, maka $H=\frac{1}{6}\left(\frac{G-B}{\delta}\right)$

Jika $G=V$, maka $H=\frac{1}{6}\left(2+\frac{B-R}{\delta}\right)$

Jika $B=V$, maka $H=\frac{1}{6}\left(4+\frac{R-G}{\delta}\right)$ 
Jika $H$ bernilai negatif, maka akan ditambahkan 1. Pada kasus khusus, $(\mathrm{R}, \mathrm{G}, \mathrm{B})=(0,0,0)$, (Atmojo, 2016) dimana kedua $V=$ lamda $=0$, maka didefinisikan $(\mathrm{H}, \mathrm{S}, \mathrm{V})=(0,0,0)$.

Misalnya diberikan $(\mathrm{R}, \mathrm{G}, \mathrm{B})=(0.2,0.4,0.6)$, sehingga

$$
\begin{aligned}
& V=\max (0.2,0.4,0.6)=0.6 \\
& \delta=\mathrm{V}-\min (0.2,0.4,0.6)=0.6-0.2=0.4 \\
& S=\frac{0.4}{0.6}=0.6667
\end{aligned}
$$

Karena $B=V$, memiliki

$$
\mathrm{H}=\frac{1}{6}\left(4+\frac{0.2-0.4}{0.4}\right)=0.5833
$$

Konversi ini diimplementasikan dalam MATLAB menggunakan fungsi rgb2hsv. Fungsi ini tentunya didesain untuk array berukuran $\mathrm{m} \times \mathrm{n} \times 3$, dalam kasus ini hanya untuk membuktikan hasil hitungan di atas:
rbg $2 \mathrm{hsv}([0.20 .40 .6])$
ans $=0.5833$
0.6667
0.6000

dan dihasilkan nilai HSV sama dengan yang telah dihitung secara manual. Untuk menghitung nilai HSV menjadi RGB, didefinisikan:

$$
\begin{aligned}
& H^{\prime}=[6 H] \\
& F=6 H-H^{\prime} \\
& P=V(1-S) \\
& Q=V(1-S F) \\
& T=V(1-S(1-F))
\end{aligned}
$$

Karena $\mathrm{H}^{\prime}$ adalah suatu integer antara 0 sampai 5, maka ada enam kasus yang perlu diperhatikan matrik berikut:

\begin{tabular}{c|ccc}
$\mathrm{H}^{\prime}$ & $\mathrm{R}$ & $\mathrm{G}$ & $\mathrm{B}$ \\
\hline 0 & $\mathrm{~V}$ & $\mathrm{~T}$ & $\mathrm{P}$ \\
1 & $\mathrm{Q}$ & $\mathrm{V}$ & $\mathrm{P}$ \\
2 & $\mathrm{P}$ & $\mathrm{V}$ & $\mathrm{T}$ \\
3 & $\mathrm{P}$ & $\mathrm{Q}$ & $\mathrm{V}$ \\
4 & $\mathrm{~T}$ & $\mathrm{P}$ & $\mathrm{V}$ \\
5 & $\mathrm{~V}$ & $\mathrm{P}$ & $\mathrm{Q}$
\end{tabular}

Kemudian nilai-nilai HSV yang telah dihitung di atas dipakai untuk menentukan nilai:

$$
\begin{aligned}
& H^{\prime}=[6(0.58333)]=3 \\
& F=6(0.58333)-3=0.5 \\
& P=0.6(1-0.6667)=0.2 \\
& Q=0.6(1-(0.58333)(0.5))=0.4 \\
& T=0.6(1-58333)(1-0.5))=0.4 \\
& \text { Karena } \mathrm{H}^{\prime}=3, \text { maka dimiliki } \\
& (R, G, B)=(P, Q, V)=(0.2,0.4,0.6)
\end{aligned}
$$

\subsection{Implementasi Sistem}

Implementasi sistem merupakan proses pembuatan sistem berupa perancangan aplikasi penentuan tingkat buta warna pada citra Ishihara dengan HSV dan algoritma Color Filtering: 1. Plate Ishihara baru

Tampilan tabel warna pada ruang HSV mengunakan color filtering, ditunjukkan pada Tabel 2 dan Tabel 3 . 
Tabel 2. Ishihara original dalam ruang warna HSV

\begin{tabular}{|ll} 
Color Color Code Percentage \\
\hline $\mathrm{d} 8 \mathrm{~d} 8 \mathrm{a} 8$ & 0.085644444444444 \\
\hline 907848 & 0.070177777777778 \\
\hline $\mathrm{d} 8 \mathrm{c} 060$ & 0.060177777777778 \\
\hline $\mathrm{a} 8 \mathrm{a} 878$ & 0.057022222222222 \\
\hline 606030 & 0.0496 \\
\hline $\mathrm{c} 0 \mathrm{c} 090$ & 0.0468444444444444 \\
\hline 909060 & 0.040533333333333 \\
\hline f0f0c0 & 0.03271111111111 \\
\hline f0f0f0 & 0.019644444444444 \\
\hline f09048 & 0.017422222222222 \\
\hline
\end{tabular}

Tabel 3. Plate Ishihara baru dalam ruang warna HSV

\begin{tabular}{|ll} 
Color Color Code Percentage \\
\hline $\mathrm{a} 8 \mathrm{~d} 8 \mathrm{c} 0$ & 0.10146464646465 \\
609060 & 0.10126262626263 \\
487860 & 0.081212121212121 \\
\hline $90 \mathrm{c} 0 \mathrm{a} 8$ & 0.08020202020202 \\
\hline $\mathrm{c} 0 \mathrm{f} 0 \mathrm{~d} 8$ & 0.06530303030303 \\
\hline $78 \mathrm{~d} 890$ & 0.051717171717172 \\
\hline $78 \mathrm{a} 890$ & 0.05010101010101 \\
\hline fofof0 & 0.045707070707071 \\
\hline $60 \mathrm{~d} 830$ & 0.023939393939394 \\
\hline $78 \mathrm{~d} 848$ & 0.020858585858586
\end{tabular}

2. Proses pembuatan plate baru

Tampilan pembuatan plate ishihara baru, ditujukan pada Gambar 4.

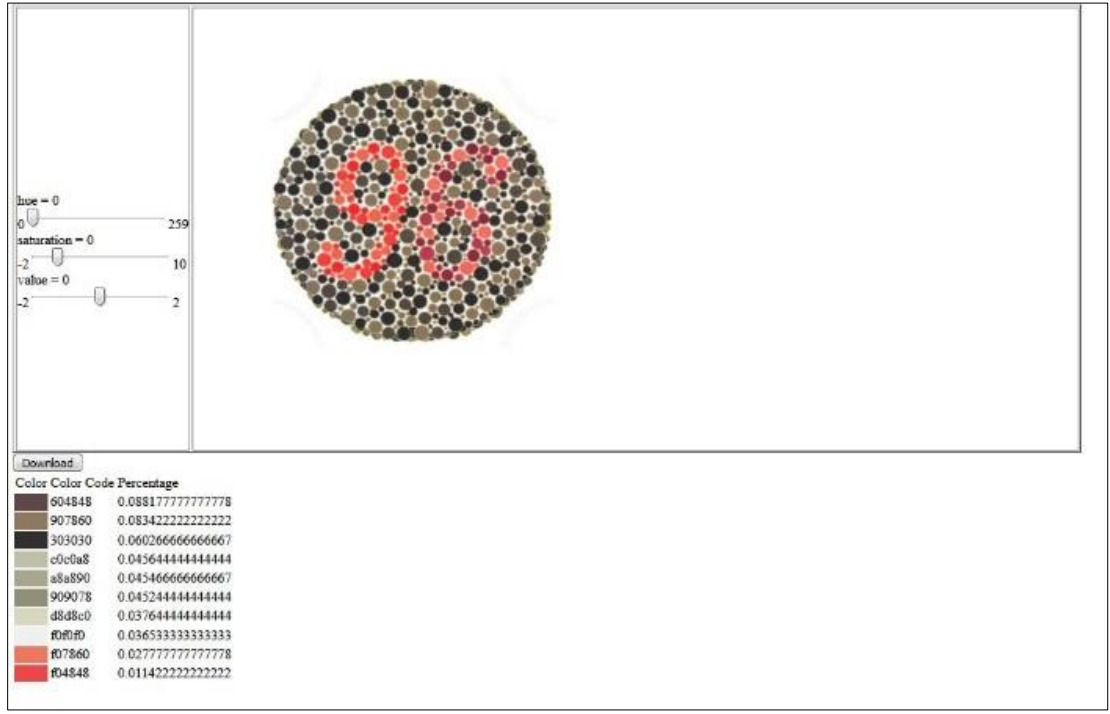

Gambar 4. Proses pembuatan plate baru

\subsection{Pengujian Sistem}

Dalam penelitian ini telah diuji dengan 30 responden tes buta warna untuk membandingkan hasil yang diperoleh baik melalui sistem manual maupun hasil yang diperoleh dari system aplikasi. Berdasarkan dari uji coba tersebut, dari keseluruhan hasil perbandingan antara hasil penentuan buta warna menurut ahli buta warna dengan hasil luaran sistem aplikasi memiliki kesamaan hasil. Berikut rekapitulasi pengujian validitas pada Tabel 4. 
Tabel 4. Pengujian validitas

\begin{tabular}{|c|c|c|c|c|c|c|c|c|}
\hline \multirow{2}{*}{ No } & \multirow{2}{*}{ Nama Peserta Uji } & \multicolumn{3}{|c|}{ Nilai Hasil Aplikasi } & \multicolumn{3}{|c|}{ Nilai Hasil Buku } & \multirow{2}{*}{ Hasil } \\
\hline & & Normal & Persial & Mono & Normal & Persial & Mono & \\
\hline 1 & Peserta \#1 & 100 & 0 & 0 & 100 & 0 & 0 & Sama \\
\hline 2 & Peserta \#2 & 100 & 0 & 0 & 100 & 0 & 0 & Sama \\
\hline 3 & Peserta \#3 & 100 & 0 & 0 & 100 & 0 & 0 & Sama \\
\hline$\ldots$ & $\ldots$ & $\ldots$ & $\ldots$ & $\ldots$ & $\ldots$ & $\ldots$ & $\ldots$ & $\ldots$ \\
\hline 30 & Peserta \#30 & 60 & 40 & 0 & 60 & 40 & 0 & Sama \\
\hline
\end{tabular}

\section{KESIMPULAN DAN SARAN}

\subsection{Kesimpulan}

Berdasarkan hasil pengujian telah diujicoba pada aplikasi pada bab sebelumnya maka dapat disimpulkan bahwa penerapan algoritma Color Filtering pada citra Ishihara berbasis HSV dapat memperoleh hasil yang sangat relevan untuk mendeteksi tingkat buta warna seseorang.

\subsection{Saran}

Adapun saran-saran atas penulisan naskah penelitian ini adalah sebagai berikut :

1. Ketepatan dalam pembuatan data plate perlu diperhatikan agar tidak terjadi kesalahan dalam proses uji.

2. Penyetingan ruang HSV masih memiliki banyak fitur lain, dan potensial untuk di kembangkan.

\section{DAFTAR PUSTAKA}

Andriessen, D. R. (2013). Pengendalian Mobile Robot Berbasis Webcam Menggunakan Perintah Isyarat Tangan. STIKOM Surabaya.

Atmojo, H. S. (2016). Aplikasi Diagnosa Kebutaan Warna Menggunakan Metode Ishihara untuk Android. Universitas Muhammadiyah Surakarta.

Kadir, A., \& Susanto, A. (2013). Teori dan Aplikasi Pengolahan Citra, Yogyakarta. Andi.

Mutrofin, S., Kurniawan, E., \& Agustiawan, Y. (2015). Ekstraksi Fitur Warna Menggunakan Hue Saturation Value Untuk Klasifikasi Tumbuhan Berdasarkan Citra Daun. https://doi.org/10.13140/RG.2.2.24846.66884

Nana, A., Rosmala, D., Ichwan, M., \& Indarko, R. W. (2016). Implementasi Algoritma Color Filtering Pada Aplikasi Gitar Virtual. Selisik, 2503-2844(Selisik), 254-262.

Prabawati, P. (2015). Sistem Pakar Diagnosa Buta Warna Berbasis Android. Universitas Negeri Semarang.

Purnamasari, P. (2015). Tes Buta Warna Metode Ishihara Berbasis Komputer. Jurnal Komputer, 38-45.

Sulistyawati, D. H. (2018). Analisa Citra Parasit Malaria Dalam Ruang Warna Hue Saturation Value ( HSV ). Jurnal Hasil Penelitian LPPM Untag Surabaya, 03(01), 6366. 